\title{
Sosyal Medya Pazarlama Faaliyetlerinin Tüketici Temelli Marka Değeri Boyutları Üzerine Etkisi
}

\section{The Effect Of Social Media Marketing Activities On Consumer Based Brand Equity Dimensions}

\author{
Bulut Dülek ${ }^{\text {a, }}$, Mehmet Emin Yaşar ${ }^{\text {b }}$ \\ ${ }^{a}$ Dr. Öğr. Üyesi, Van Yüzüncü Y1l Üniversitesi, İktisadi ve İdari Bilimler Fakültesi, İşletme Bölümü, 65000, Van/Türkiye. \\ ORCID: 0000-0002-3474-7220
}

'Öğr. Gör., Bingöl Üniversitesi, Solhan SHMYO, Sağlık Bilimleri Fakültesi, İș Sağllğı ve Güvenliği Bölümü, 12400, Bingöl/Türkiye. ORCID: 0000-0001-8137-2946.

\section{MAKALE BİLGİSI}

Makale Geçmişi:

Başvuru tarihi: 28 Mayıs 2020

Düzeltme tarihi: 20 Mart 2021

Kabul tarihi: 28 Mart 2021

Anahtar Kelimeler:

Tüketici Temelli Marka Değeri

Marka

Sosyal Medya

\section{ART ICLE INFO}

\section{Article history:}

Received: May 28, 2020

Received in revised form: March 20, 202021

Accepted: March 28, 2021

\author{
Keywords: \\ Consumer-Based Brand Equity \\ Brand, \\ Social Media
}

\begin{abstract}
ÖZ
İşletmeler açısından markalarıyla ilgili farkındalık ve çağrışım oluşturma, algılanan kaliteyi artırma ve marka sadakat düzeyini genişletme gibi rekabet avantajı sağlayacak faaliyetlerin sürdürülmesinde sosyal medya araçları önemli bir yere sahiptir. Bu çalışmada işletmelerin sosyal medya pazarlamasına yönelik faaliyetlerinin tüketici temelli marka değeri boyutları üzerine etkisi analiz edilmektedir. $\mathrm{Bu}$ amaç doğrultusunda sosyal medya araçlarını sıklıkla kullanan üniversite öğrencilerinin markalara yönelik algılamaları ve davranışları analiz edilmeye çalışılmıştır. Araştırma Bingöl Üniversitesinde öğrenim görmekte olan 349 öğrenci ile yüz yüze görüşme yapılarak uygulanan anket metoduyla gerçekleştirilmiştir. Verilerin analiz edilmesi ve araştırma hipotezlerinin test edilmesinde ise doğrulayıcı faktör analizi ve yapısal eşitlik modellemesi uygulanmıştır. Elde edilen bulgular sonucunda sosyal medya pazarlama faaliyetlerinin tüketici temelli marka değeri boyutları üzerinde anlamlı bir etkisi olduğu sonucuna ulaşılmıştır.
\end{abstract}

\begin{abstract}
A B S T R A C T
Social media tools play an important role in sustaining activities that will provide competitive advantage such as creating awareness and association about their brands, increasing perceived quality and expanding brand loyalty. In this study, the effects of the activities of the businesses for social media marketing on the consumer-based brand equity dimensions were analyzed. For this purpose, it was tried to analyze the perceptions and behaviors of university students who used social media tools frequently. The research was carried out with the face-to-face interviews with 349 students studying at Bingöl University, using the survey method. Confirmatory factor analysis and structural equation modeling were used to analyze the data and test the hypotheses. As a result of the findings, it was found that social media marketing activities had a significant effect on consumerbased brand equity dimensions.
\end{abstract}

\section{Giriş}

Sosyal medya, Web 2.0'in ideolojik ve teknolojik temelleri üzerine inşa edilen, kullanıcılarının içerik oluşturmasına ve kolaylıkla etkileşim içinde olmalarına imkân sağlayan internet tabanlı bir uygulamadır (Kaplan ve Haenlein, 2010). Sosyal medya araçlarının günümüz dünyasında daha yaygın kullanılmasıyla birlikte dünya daha da küçülmüş ve insanlar arasındaki etkileşim daha da artmış bulunmaktadır. Bu bağlamda sosyal medya araçları reklam, pazarlama stratejileri ve satın alma alışkanlıkları gibi pazarlama faaliyetleri üzerinde de etkileri olmaktadır.

Pazarlama çabalarında sosyal medya araçlarının kullanılması işletmelerin marka değerini ve tüketicilerin markaya yönelik yaklaşımlarını da etkilemektedir. Tüketici odaklı yaklaşımla marka değeri, tüketicinin markaya yönelik bakış açısıyla o markadan elde ettiği memnuniyetin bütünleşmiş hali olarak ifade edilmektedir (Blackston, 1992: 82). Tüketici temelli marka değeri birçok çalışmada marka

\footnotetext{
* Sorumlu yazar/Corresponding author.

e-posta: meyasarbingol.edu.tr
} 
farkındalığı, marka çağrışımları, algılanan kalite ve marka sadakati boyutlarıyla ele alınmaktadır.

Sosyal medya araçlarının kullanılması geniş kitlelere markaların ulaştırılmasını daha kolay hale getirebilmektedir. $\mathrm{Bu}$ çalışmada sosyal medya pazarlama faaliyetlerinin tüketici temelli marka değeri boyutları (marka farkındalığı, marka çağrışımları, algılanan kalite ve marka sadakati) üzerine etkisi analiz edilmeye çalışılmıştır. $\mathrm{Bu}$ amaç doğrultusunda sosyal medya araçlarını daha sık kullanmalarından dolayı araştırmanın örneklemi üniversite öğrencilerinden oluşmaktadır. Hem işletmeler hem de alan yazınında yapılacak çalışmalar açısından bu çalışmanın sosyal medya araçlarının kullanımı ve önemi konusunda farklı bir bakış açısı kazandıracağı öngörülmektedir. Bu çalışmanın birinci kısmında kavramsal çerçeve ve hipotezlerin geliştirilmesi yer almaktadır. İkinci kısımda ise Bingöl Üniversitesi öğrencileri üzerinde yapılan araştırmanın metodolojisi bulunmaktadır.

\section{Teorik Çerçeve}

\subsection{Sosyal Medya Pazarlaması}

Sosyal medya pazarlaması, bir marka, işletme, ürün, kişi veya başka bir tüzel kişi için farkındalık oluşturup tüketicileri eyleme geçirmeyi amaçlayan ve bloglama, sosyal ağ oluşturma, içerik paylaşımı gibi araçları kullanarak yürütülen doğrudan veya dolaylı pazarlama olarak tanımlanmıştır. Ticari organizasyonların müşterileri ile başarılı, uzun süreli ve katma değerli bir ilişki sürdürmeleri için geniş alan sağlayan yeni pazarlama yaklaşımıdır (Gunelius, 2010). Sosyal medya web sitesini kullananların imkan veren online bir ağ sitesidir (Baydaş, Ata, ve Berdibek,2021:189).

Thakur ve Kumar (2018: 215) sosyal medya pazarlamasını, büyük sosyal medya platformlarında varlık gösterme, paylaşılabilir içerik ve reklamlar hazırlama ve bu sayede müşteri geri bildirimlerini teşvik etmek amacıyla gerçekleştirilen pazarlama çabaları olarak ifade etmektedirler.

Sosyal medya sayesinde işletmelerin reklamcılık ve pazarlama uygulamaları daha çeşitli hale gelmiş bulunmaktadır. Sosyal medya pazarlaması işletmelerin müşterilerinin geri bildirimlerini, yorumlarını ve önerilerini almasını ve müşteri ihtiyaçlarının daha proaktif bir şekilde ele alınabilmesi için ürün ve hizmetlerini geliştirmesini sağlamıştır (Hajli, 2014: 392). Sosyal medya araçları ile işletmelerin markalarını daha geniş küresel topluluklara pazarlaması da sağlanmıştır. Sosyal medya platformları her ülkeden herkes için açık ve erişilebilirdir bu nedenle şirketlere topluluklarla iletişim kurma ve hedef kitleleriyle ilişki kurma konusunda muazzam firsatlar sunmaktadır (Kabani ve Brogan, 2010).

Sosyal medyada, işletmelerin ve bireylerin katılabilmeleri için bir araç olarak kullanabilecekleri birçok sosyal ağ aracı vardır. Facebook, Twitter, YouTube ve Blogcular dünya çapında insanlar tarafından kullanılan popüler sosyal medya aracıdır (Sin vd., 2012).

\subsection{Tüketici Temelli Marka Değeri Boyutları}

Marka değerinin sadece finansal bir çıktı olarak değil tüketici algılamalarını da dikkate alarak değerlendirilmesini esas alan yaklaşımlarla birlikte tüketici temelli marka değeri kavramı literatüre girmiştir. Aaker (1991)'e göre tüketici temelli marka değeri, ürün veya hizmet tarafından bir işletmeye veya işletmenin müşterilerine sağlanan değeri arttırmada veya azaltmada markayla ilişkili tüm varlıkların oluşturduğu topluluğu ifade etmektedir.

Tüketici temelli marka değeri, hedef tüketici gruplarının istek ve ihtiyaçları doğrultusunda markaya ilave edilen değerdir (Farquhar 1989: 25). Tüketicilerin artan fayda ile sonuçlanan ve bir markanın, marka adı olmadan elde edebileceğinden daha fazla hacim veya daha fazla marj kazanmasina izin veren bir dizi alg1, tutum, bilgi ve davranıştır (Christodolides ve Chernatory, 2010).

Tüketicinin markaya yönelik algılama veya bilgilerine göre şekillenen, işletmelerin pazarlama kararlarını da aynı şekilde etkileyen, tüketici deneyimi ile pazarlama çabaları arasındaki olumlu olumsuz etkileşime neden olan bir olgudur (Biyan, 2019:152). Tüketici temelli marka değerini oluşturan farklı boyutlar bulunmaktadır. Bu boyutlardan en sık kullanılan ve kabul görenleri marka farkındalığı, marka çağrışımları, algılanan kalite ve marka sadakatidir.

Marka farkındalığı, potansiyel bir alıcının bir markanın belirli bir ürün kategorisinin üyesi olduğunu ayırt edebilme yeteneği olarak tanımlanmaktadır. Marka değeri oluşturmanın ilk adımı marka farkındalığı ile başlamaktadır. Bir markanın tanınma ve hatırlanma derecesi o markanın farkındalık düzeyi ile ilgilidir. Güçlü farkındalığa sahip ve akılda kalıcı bir marka, müşterilerin algılarını etkileyebilir ve bu sayede daha geniş hedef kitlelere ulaşılmış olunur (Aaker, 1991; Keller, 1993; Kimpakorn ve Tocquer, 2010).

Marka çağrışımları marka ile ilgili tüm düşünce, duygu, algı, imaj, deneyim, inanç ve tutumlardan oluşmaktadır (Kotler ve Keller, 2006). Marka çağrışımları markanın iletişim yönüyle ilişkilidir. Markaya ait özelliklerin tüketiciler tarafından nasıl algılandığını ifade etmektedir.

Marka çağrışımları işletmeler açısından farklılaştırma sağlama, markayı konumlandırma ve markaya karşı pozitif tutumlar geliştirmeye aracı olarak değerlendirilmektedir. Tüketiciler için ise bilgileri hatırlama, bu bilgileri organize etme ve satın alma kararlarını kolaylaştırmak amacıyla kullanılmaktadır (Low ve Lamb, 2000: 351).

Alg1lanan kalite, müşterinin bir ürünün genel mükemmellik veya üstünlügü hakkında nesnel kaliteden farklı olan ve müşterinin algısıyla ilgili yargısıdır (Tang ve Hawley, 2009). Algılanan kalite bir ürünün sahip olduğu özelikleri, üstün yanları ve rakip ürünlere göre benzersiz oluşu konusunda tüketicilerin sahip olduğu bakış açılarını, yargı ve değerlendirmeleri ifade eden sübjektif ve soyut bir kavramdır. Gerçek kalite ile algılanan kalite aynı kavramlar olmamasına rağmen birbiriyle ilişkilidirler. Genellikle algılanan kalitenin temelinde gerçek kalite önemli bir etmen olarak değerlendirilmektedir (Kocatürk, 2017).

Marka sadakati, müşterinin markaya bağlılık derecesi olarak ifade edilmektedir. Müşterinin rakip işletmeler tarafindan sunulmuş olan daha uygun fiyat ve promosyon teklifleri karşısında bile bir markayı satın almaya yönelik kararlı yaklaşımıdır (Aaaker, 1991; Palumbo ve Herbig, 2000:116). Marka sadakati tesadüfi olarak gerçekleşen bir tutum değildir. Müşterilerin bilinçli olarak birçok marka arasından birisini davranışsal tepki olarak sürekli tercih etmesidir. 
Marka sadakatinin yüksek düzeyde olması durumu tüketici temelli marka değerinin en önemli belirleyicisidir.

\section{Hipotezlerin Geliştirilmesi}

Markalar sosyal medya pazarlamasını kullanarak tüketicilere daha kolay ulaşabilmekte ve marka değerini artırmaya yönelik çabaları daha anlamlı hale getirebilmektedirler. Tüketicilerin bir ürün veya hizmet hakkında aktif olarak bilgi aradıkları ve satın almadan önce deneyim yaşayabildikleri sosyal medya platformları marka değeri boyutları üzerinde de etkilidir.

Sosyal medya pazarlaması ile marka değeri arasında anlamlı bir ilişki bulunmaktadır. İşletmeler sosyal medya araçlarındaki çevrimiçi etkinlikleri ile temel özelliklerini tanımlayıp kullanarak marka değerini artırmalarına katkıda bulunmaktadırlar (Kavisekera ve Abeysekera, 2016).

Tüketicilerin sosyal medya içeriklerine yönelik aktif katılımları ile işletmeler arasındaki etkileşimleri de artacaktır. Sosyal medyadaki etkili kampanyalar, işletmelerin tüketicilere sunmuş oldukları faydalar, değerler ve avantajlarla marka sadakatini pozitif yönde etkilemektedir (Balakrishan vd., 2014; Erdoğmuş ve Çiçek, 2012).

Sosyal medya pazarlamasının eğlence, etkileşim, eğilim, kişiselleştirme ve ağızdan ağıza iletişim etkinlikleri lüks markalar açısından marka değerini, marka farkındalığını ve marka imajını etkilemektedir (Godey vd., 2016). İşletmeler sosyal medya pazarlamasını pazarlama stratejilerine entegre etmekle müşterileriyle iletişimi ve etkileşimi daha da geliştirmeyi, markalarının farkındalıklarının artırmayı başarabilirler (Elaydi, 2018).

Mousavi ve arkadaşları (2015), yapmış oldukları araştırmada sosyal medyanın müşterilerin ilişkileri üzerinde olumlu etkilere sahip olduğunu ve bunun da marka güvenini ve marka sadakatini olumlu etkilediğini ifade etmişlerdir.

Sosyal medya giderek daha fazla geleneksel medyanın yerini alıyor ve daha fazla tüketici bunları ürünler, hizmetler ve markalar hakkında bilgi kaynağı olarak kullanıyor (Baydaş ve Yaşar, 2019). Bu bağlamda yapılan amprik çalışmada sosyal medya pazarlamasının Sri Lanka Seyahat ve Turizm Endüstrisinde marka değeri üzerinde güçlü bir olumlu etkisi olduğu sonucuna ulaşıllmıştır (Ajanthan, 2017).

Sosyal medya platformlarında kurgusu doğru şekilde oluşturulmuş etkin bir interaktif iletişim, tüketicilere ait marka değer algılarını olumlu yönde etkileyecektir. Sosyal medya iletişiminin alt boyutları ile tüketici temelli marka değeri arasında orta kuvvette ve anlamlı ilişkilerin olduğu tespit edilmiştir (Çakırkaya ve Koçyiğit, 2019).

Sosyal medya platformlarından Facebook'ta gerçekleştirilen bilgilendirici etkinliklerin, ağızdan ağıza iletişim ve müşteri ilişkileri çanbalarının marka değeri boyutları olan algılanan kalite, marka farkındalığı ve çağrışımları ile marka sadakati üzerinde etkilerinin olduğu sonucuna ulaşılmıştır (Gümüş vd., 2013).

Birçok işletme sosyal medyayı, ürünlerini tanıtmak ve dikkat çekici çağrışımlar oluşturmak amacıyla kullanmaktadırlar. Sosyal medya platformları aracılığıyla oluşturulan içerik ve mesajlar, kullanıcıların marka çağrışım boyutu algılamalarında anlamlı değişliklere neden olmaktadır (Andehn vd., 2014).

Sosyal medya uygulamaları tüketici marka ilişkisini etkilediği gibi tüketicilerin birbirleriyle olan ilişkilerini etkilemektedir. Söz konusu bu durumla birlikte markaya bağlı tüketicilerin sayısı da artmaktadır (Luo vd., 2015).

Alan yazınında daha önceki dönemlerde yapılan birçok çalışma analiz edildiğinde sosyal medya pazarlaması ile tüketici temelli marka değeri boyutları arasında ilişkinin olduğu söylemek mümkündür. $\mathrm{Bu}$ teorik çerçeveler doğrultusunda araştırma hipotezleri şu şekilde kurgulanmıştır:

$\mathbf{H}_{1}$ : Sosyal medya pazarlaması marka farkındalığı üzerinde etkilidir.

H2: Sosyal medya pazarlaması marka çağrışımları üzerinde etkilidir.

H3: Sosyal medya pazarlaması algılanan kalite üzerinde etkilidir.

H4: Sosyal medya pazarlaması marka sadakati üzerinde etkilidir.

\section{Araştırma Yöntemi}

\subsection{Araştırmanın Amacı ve Önemi}

$\mathrm{Bu}$ araştırma işletmelerin gerçekleştirdikleri sosyal medya pazarlama faaliyetlerinin tüketici temelli marka değeri boyutlarını etkileyip etkilemediğini analiz etmek amacıyla yapılmıştır. Marka değeri çok sayıda markanın olduğu ve rekabetin daha yoğun olduğu Pazar şartlarında işletmeler için önemli bir farklılaşma aracıdır. Tüketicilerin zihinlerinde ayrıcalıklı bir konuma sahip olan ve onları kendi organizasyonlarına bağlı hale getiren işletmeler daha kalıcı olmaktadırlar. İşletmeler açısından sosyal medya pazarlama faaliyetlerinin daha geniş kitlelere ulaşmanın yanında markalarıyla ilgili farkındalık ve çağrışım oluşturma, algılanan kaliteyi artırma ve marka sadakat düzeyini genişletme gibi olumlu sonuçları da söz konusudur. Bu araştırmanın bu yaklaşımlar doğrultusunda hem işletmelere hem de alan yazınındaki çalışma arkadaşlarımıza sosyal medya araçlarının kullanımı ve önemi konusunda farklı bir bakış açısı kazandıracağı öngörülmektedir.

\subsection{Araştırma Metodu ve Örneklem Süreci}

Araştırmanın yapılabilmesi için Bingöl Üniversitesi etik kurulu onayı (say1: 92342550/044/, tarih: 03.06.2020) etik kurul yönergesi ilkeleri çerçevesinde değerlendirilmiş ve araştırma etiği açısından uygun olduğuna ve çalışmanın yapılmasına karar verilmiştir. Bu çalışma için gerekli veriler anket tekniği kullanılarak toplanmıştır. Bu yöntemin tercih edilmesinin nedeni, veri toplama sürecinin daha etkin bir şekilde yönetilebilmesi ve verilerin bu yöntemle kolayca analiz edilebilmesidir. Araştırmanın ana kütlesini Bingöl Üniversitesi yerleşkesi içinde öğrenim gören üniversite öğrencileri oluşturmaktadır. Bingöl Üniversitesi Öğrenci İşleri Daire Başkanlığından alınan resmi yazıya göre üniversitenin merkez yerleşkesinde öğrenim gören öğrenci say1s1 15713 'dir.

Ana kütlenin tamamına ulaşmak mümkün olamayacağından dolayı örneklem oluşturma yoluna gidilmiştir. Örneklem, var 
olan bir ana kütleden onu temsil edebilecek daha küçük sayıdaki gruplardır (Kaplan, 1998).

Ana kütle sayısı dikkate alındığında araştırmanın örneklem büyüklüğünün \%95 güven aralığında en az 322 olması gerekmektedir (Thornhill vd., 2009). Anket formu Bingöl Üniversitesi yerleşkesi içinde farklı bölümlerde öğrenim görmekte olan 400 öğrenciye yüz yüze görüşme yöntemiyle uygulanmıştır. Hatalı ve eksik bilgilerin olduğu anketler elimine edilerek analize toplam 349 anket dahil edilmiştir. Anket formunda toplam 24 soru bulunmaktadır. Demografik sorular dışında 5'li Likert ölçeğinde sunulan 19 ifade bulunmaktadır. Sosyal medya pazarlaması için çalışma Bong (2017) ve Erdoğmuş ve Çiçek (1992) tarafından önerilen çerçeveye dayandırılmıştır. Tüketici temeli marka değeri boyutları için ise Yoo ve Donthu (2001) tarafindan geliştirilmiş ölçeğe dayanmaktadır.

\section{Analiz ve Bulgular}

\subsection{Demografik Bulgular}

Tablo 1. Demografik Özelliklere İlişkin Bulgular

\begin{tabular}{|c|c|c|c|}
\hline $\begin{array}{l}\text { Demografi } \\
\text { k Özellik }\end{array}$ & Grup & $\begin{array}{c}\text { Freka } \\
\text { ns }\end{array}$ & $\begin{array}{c}\text { Yüzde } \\
(\%)\end{array}$ \\
\hline \multirow{3}{*}{ Cinsiyet } & Kadın & 208 & 59,6 \\
\hline & Erkek & 141 & 40,4 \\
\hline & Toplam & 349 & 100 \\
\hline \multirow{5}{*}{ Yaş } & 18 yaş altı & 6 & 1,7 \\
\hline & 18-21 yaş arası & 177 & 50,7 \\
\hline & $22-25$ yaş aras1 & 144 & 41,3 \\
\hline & 26 yaş ve üzeri & 22 & 6,3 \\
\hline & Toplam & 349 & 100 \\
\hline \multirow{4}{*}{$\begin{array}{l}\text { Öğrenim } \\
\text { Durumu }\end{array}$} & Ön lisans & 94 & 26,9 \\
\hline & Lisans & 238 & 68,2 \\
\hline & Lisansüstü & 17 & 4,9 \\
\hline & Toplam & 349 & 100 \\
\hline \multirow{5}{*}{$\begin{array}{c}\text { Aylık } \\
\text { Harcama } \\
\text { (TL) }\end{array}$} & 300 TL'den az & 29 & 8,3 \\
\hline & 300-499 TL aras1 & 108 & 31,0 \\
\hline & $500-1000$ TL aras 1 & 190 & 54,4 \\
\hline & 1000 TL ve üzeri & 22 & 6,3 \\
\hline & Toplam & 349 & 100 \\
\hline \multirow{8}{*}{$\begin{array}{c}\text { En Sık } \\
\text { Kullanılan } \\
\text { Sosyal } \\
\text { Medya } \\
\text { Aracı }\end{array}$} & Facebook & 40 & 11,5 \\
\hline & Google+ & 50 & 14,3 \\
\hline & Instagram & 178 & 51,0 \\
\hline & Twitter & 31 & 8,9 \\
\hline & Linkedin & 10 & 2,9 \\
\hline & Youtube & 3 & ,9 \\
\hline & Diğger & 37 & 10,6 \\
\hline & Toplam & 349 & 100 \\
\hline
\end{tabular}

Katılımcıların \%59,6'sı kadın ve \%40,4'ü erkektir. Katılımcıların \%50,7'si 18-21 yaş aralığında, \%68,2' si lisans düzeyinde öğrenim görmektedir. Aylık harcama miktarının \%54,4'ü 500-1000 TL arasındadır. Katılımcılar tarafindan en sık kullanılan sosyal medya aracı ise \%51,0 oranla Instagramdir.

\subsection{Doğrulayıcı Faktör Analizi ve Güvenilirlik Bulguları}

Faktör dağılımlarının uygunluğunu ölçmek amacıyla doğrulayıcı faktör analizi yapılmıştır. Analiz sonucunda elde edilen doğrulayıcı analiz modeli ve uyum indeksleri Şekil-1 ve Tablo-2'de gösterilmektedir. Bununla beraber Tablo-2' de standartlaştırılmış faktör ağırlıkları, $\mathrm{t}$ ve $\mathrm{R}^{2}$ anlamlılık değerleri, ortalama açılanan varyans (AVE), birleşik güvenilirlik (CR) ve Cronbach Alfa değerleri yer almaktadır.

Sosyal medya pazarlaması, marka farkındalığı, marka çağrışımları, algılanan kalite ve marka sadakati boyutlarının ölçümünde kullanılan değişkenler, ilgili oldukları faktörü $\mathrm{p}<0,01$ anlam düzeyinde istatistiksel olarak açıklamaktadırlar. Değişkenlere ait güvenilirlik katsayıları (Cronbach Alfa) 0,648 ve 0,835 aralığında güvenilir seviyede gerçekleşmiştir.

Sosyal medya pazarlaması, marka farkındalığı, marka çağrışımları, algılanan kalite ve marka sadakati boyutlarına ilişkin birleşik güvenilirlik (CR) değerleri referans değer olan 0,70 'in üzerinde gerçekleşmiştir. Ortalama açıklanan varyans (AVE) değerlerinde ise sadece sosyal medya pazarlaması boyutu referans değer olan 0,50' nin altında gerçekleşmiştir. Hair ve arkadaşları (1998), CR değerlerinin 0,60'dan büyük olduğu durumlarda, AVE'nin 0,50'den küçük olmasının kabul edilebileceğini ve yapı geçerlilik düzeyinin yeterli olduğunu ifade etmişlerdir.

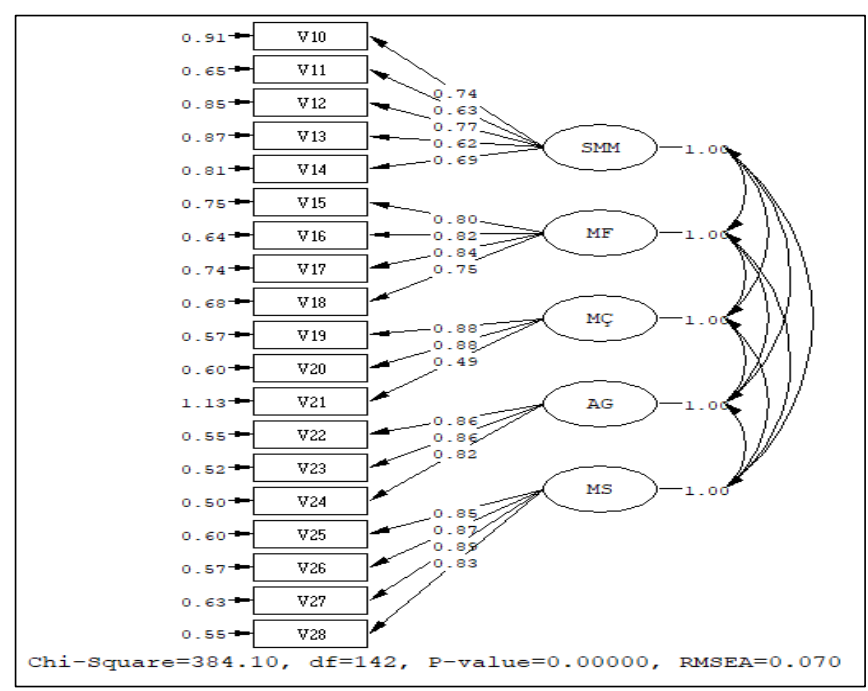

Şekil-1: Doğrulayıcı Faktör Analizi

Doğrulayıcı faktör analizi sonuçlarının uyum değerleri kriterlerini sağladığı görülmektedir. Model modifikasyonunda ki-kare değeri ( $\chi 2$ ) 384,10, serbestlik derecesi ise (sd) 142 olarak bulunmuştur (p-equity: 0,00000). Ki-kare değerinin serbestlik derecesine bölünmesiyle modifikasyon uyum değeri 2,70 ( $\leq 3)$ olarak tespit edilmiştir. Ayrıca uyum kriterleri RMSEA, SRMR, NNF, NNFI, CFI, GFI ve AGFI değerlerinin de kabul edilen uyum düzeylerinde olduğu görülmektedir (Tablo 3). 


\begin{tabular}{|c|c|c|c|c|c|c|c|}
\hline Faktör & Değişken & t Değeri & St Değeri & $\mathbf{R}^{2}$ & $\mathbf{C R}$ & AVE & $\begin{array}{c}\text { Cronbach } \\
\text { Alfa }\end{array}$ \\
\hline \multirow{5}{*}{$\begin{array}{l}\text { SOSYAL MEDYA } \\
\text { PAZARLAMASI }\end{array}$} & SMP1 & 11,45 & 0,74 & 0,38 & \multirow{5}{*}{0,82} & \multirow{5}{*}{0,48} & \multirow{5}{*}{0,743} \\
\hline & SMP2 & 11,56 & 0,63 & 0,38 & & & \\
\hline & SMP3 & 12,10 & 0,77 & 0,41 & & & \\
\hline & SMP4 & 10,22 & 0,62 & 0,31 & & & \\
\hline & SMP5 & 11,33 & 0,69 & 0,37 & & & \\
\hline \multirow{4}{*}{$\begin{array}{c}\text { MARKA } \\
\text { FARKINDALIĞI }\end{array}$} & MF1 & 13,65 & 0,80 & 0,46 & \multirow{4}{*}{0,88} & \multirow{4}{*}{0,64} & \multirow{4}{*}{0,784} \\
\hline & MF2 & 14,61 & 0,82 & 0,51 & & & \\
\hline & MF3 & 14,11 & 0,84 & 0,49 & & & \\
\hline & MF4 & 13,41 & 0,75 & 0,45 & & & \\
\hline \multirow[t]{3}{*}{ MARKA ÇAĞRIŞIMI } & MÇ1 & 15,20 & 0,88 & 0,57 & \multirow{3}{*}{0,81} & \multirow{3}{*}{0,60} & \multirow{3}{*}{0,648} \\
\hline & MÇ2 & 14,95 & 0,88 & 0,56 & & & \\
\hline & MÇ3 & 7,50 & 0,49 & 0,17 & & & \\
\hline \multirow{3}{*}{ ALGINAN KALITTE } & AK1 & 15,60 & 0,86 & 0,57 & \multirow{3}{*}{0,88} & \multirow{3}{*}{0,72} & \multirow{3}{*}{0,803} \\
\hline & AK2 & 15,91 & 0,86 & 0,59 & & & \\
\hline & AK3 & 15,64 & 0,82 & 0,57 & & & \\
\hline \multirow{4}{*}{ MARKA SADAKATİ } & MS1 & 15,32 & 0,86 & 0,55 & \multirow{4}{*}{0,91} & \multirow{4}{*}{0,74} & \multirow{4}{*}{0,835} \\
\hline & MS2 & 15,77 & 0,87 & 0,57 & & & \\
\hline & MS3 & 15,49 & 0,88 & 0,56 & & & \\
\hline & MS4 & 15,56 & 0,83 & 0,56 & & & \\
\hline
\end{tabular}

Tablo 3. Doğrulayıcı Faktör Analizi Uyum Değerleri

\begin{tabular}{|ccccc|}
\hline Uyum ölçüsü & Mükemmel Uyum & Kabul Edilebilir Uyum & Model değeri & Uyum \\
\hline $\begin{array}{c}\boldsymbol{2} / \mathbf{s} \boldsymbol{d} \\
(384,10 / 142)\end{array}$ & $\leq 3$ & $\leq 5$ & $\mathbf{2 , 7 0}$ & Mükemmel uyum \\
\hline RMSEA & $0<\mathrm{RMSEA}<0.05$ & $0.05 \leq \mathrm{RMSEA} \leq 0.10$ & $\mathbf{0 , 0 7 0}$ & Kabul edilebilir uyum \\
\hline SRMR & $0 \leq \mathrm{SRMR}<0.05$ & $0.05 \leq \mathrm{SRMR} \leq 0.10$ & $\mathbf{0 , 0 5}$ & Kabul edilebilir uyum \\
\hline CFI & $0.95 \leq \mathrm{CFI} \leq 1$ & $0.90 \leq \mathrm{CFI} \leq 0.95$ & $\mathbf{0 , 9 7}$ & Mükemmel uyum \\
\hline GFI & $0.95 \leq \mathrm{GFI} \leq 1$ & $0.90 \leq \mathrm{GFI} \leq 0.95$ & 0,90 & Kabul Edilebilir uyum \\
\hline AGFI & $0.90 \leq \mathrm{AGFI} \leq 1$ & $0.85 \leq \mathrm{AGFI} \leq 0.90$ & 0,86 & Kabul Edilebilir uyum \\
\hline NFI & $0.95 \leq \mathrm{NFI} \leq 1$ & $0.90 \leq \mathrm{NFI} \leq 0.95$ & $\mathbf{0 , 9 6}$ & Kabul edilebilir uyum \\
\hline NNFI & $0.95 \leq \mathrm{NNFI} \leq 1$ & $0.90 \leq \mathrm{NNFI} \leq 0.95$ & $\mathbf{0 , 9 5 7}$ & Kabul edilebilir uyum \\
\hline
\end{tabular}

Kaynak: (Schermelleh-Engel, Moosbrugger ve Müller, (2003))

\subsection{Yapısal Eşitlik Modellemesi}

Araştırma modeli doğrultusunda oluşturulan hipotezlerin kabul edilip edilmediğini test etmek amacıyla yol analizleri yapılarak yapısal model test edilmiştir. Yapılan analiz sonucunda elde edilen değerler Şekil-2 ve Tablo-4'te yer almaktadır. Analiz sonuçlarına göre ki-kare değerinin anlamlı çıktığ görülmektedir $(\mathrm{p}=0,000)$. Bununla beraber kikare/serbestlik derecesi $\chi 2 / \mathrm{sd}=2,80$ olarak gerçekleşmiştir. Sonucun referans değerinin 3'ün altında olması veri ile model arasında uyumun mükemmel olduğunu göstermektedir. 
Tablo 4. Yapısal Modele İlişkin Uyum Değerleri

\begin{tabular}{|ccccc|}
\hline Uyum ölçüsü & Mükemmel Uyum & Kabul Edilebilir Uyum & Model değeri & Uyum \\
\hline $\begin{array}{c}\boldsymbol{2} / \mathbf{s} \boldsymbol{d} \\
(411,37 / 147)\end{array}$ & $\leq 3$ & $\leq 5$ & $\mathbf{2 , 8 0}$ & Mükemmel uyum \\
\hline RMSEA & $0<\mathrm{RMSEA}<0.05$ & $0.05 \leq \mathrm{RMSEA} \leq 0.10$ & $\mathbf{0 , 0 7 2}$ & Kabul edilebilir uyum \\
\hline SRMR & $0 \leq \mathrm{SRMR}<0.05$ & $0.05 \leq \mathrm{SRMR} \leq 0.10$ & $\mathbf{0 , 0 5 2}$ & Kabul edilebilir uyum \\
\hline CFI & $0.95 \leq \mathrm{CFI} \leq 1$ & $0.90 \leq \mathrm{CFI} \leq 0.95$ & $\mathbf{0 , 9 7}$ & Mükemmel uyum \\
\hline GFI & $0.95 \leq \mathrm{GFI} \leq 1$ & $0.90 \leq \mathrm{GFI} \leq 0.95$ & 0,90 & Kabul Edilebilir uyum \\
\hline AGFI & $0.90 \leq \mathrm{AGFI} \leq 1$ & $0.85 \leq \mathrm{AGFI} \leq 0.90$ & 0,86 & Kabul Edilebilir uyum \\
\hline NFI & $0.95 \leq \mathrm{NFI} \leq 1$ & $0.90 \leq \mathrm{NFI} \leq 0.95$ & $\mathbf{0 , 9 6}$ & Kabul edilebilir uyum \\
\hline NNFI & $0.95 \leq \mathrm{NNFI} \leq 1$ & $0.90 \leq \mathrm{NNFI} \leq 0.95$ & $\mathbf{0 , 9 7}$ & Kabul edilebilir uyum \\
\hline
\end{tabular}

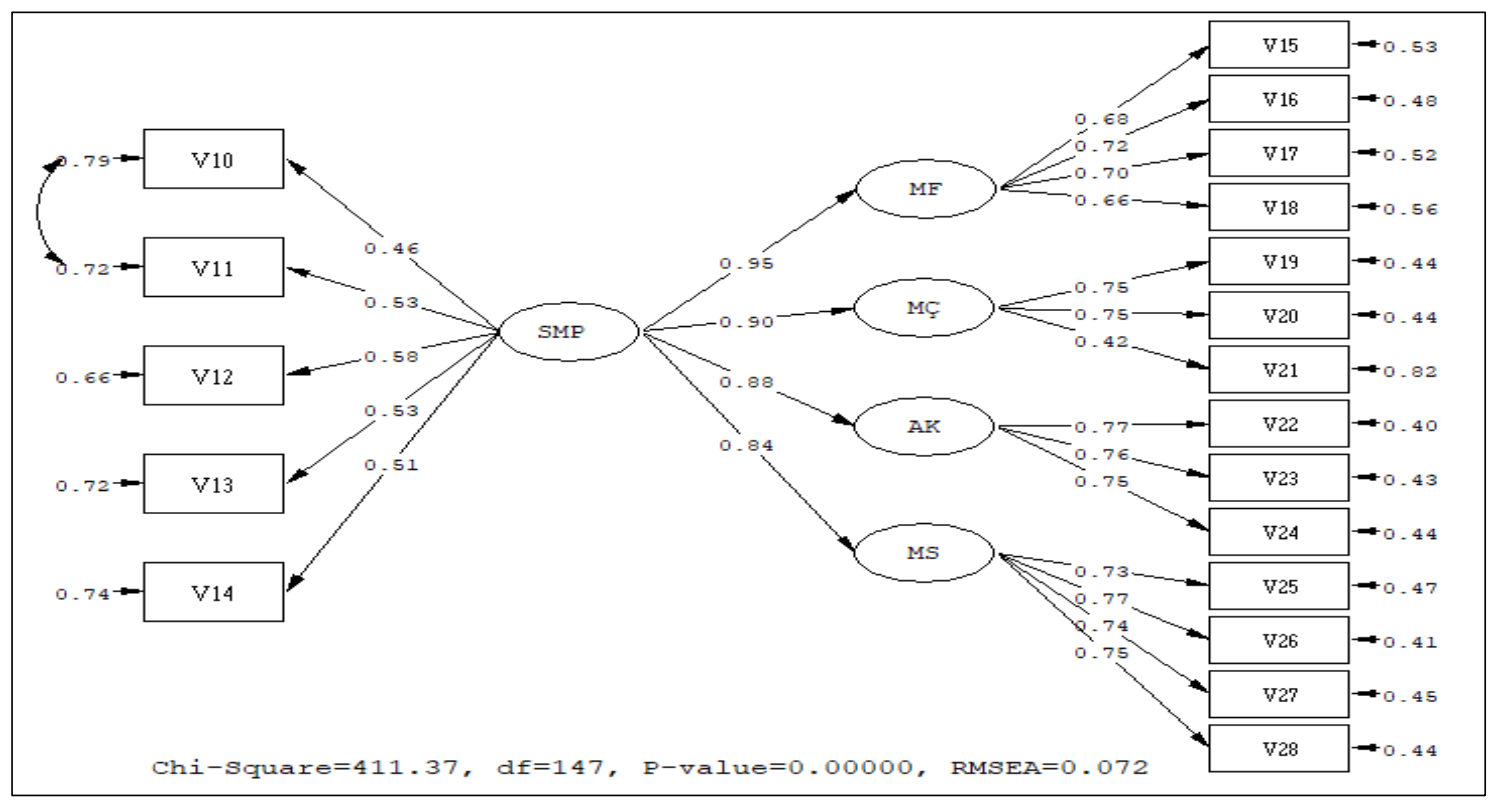

Şekil 2: Yapısal Eşitlik Modellemesi

Araştırma hipotezlerinin test edilmesi amacıyla yapılan yapısal eşitlik modellemesi sonuçlarına ilişkin değerlendirmeler aşağıdaki tablo da gösterilmektedir.

Tablo 5. Yapısal Eşitlik Modellemesi Sonuçları

\begin{tabular}{|c|c|c|c|c|c|}
\hline & Hipotezler & $\begin{array}{c}\text { t Değerleri } \\
>1,96\end{array}$ & $\begin{array}{l}\text { Standardize } \\
\text { Edilmiş } \\
\text { Değerler }\end{array}$ & $\mathbf{R}^{2}$ & Sonuç \\
\hline $\mathrm{H}_{1}$ & $\mathrm{SMP} \rightarrow \mathrm{MF}$ & 13,04 & 0,95 & 0,90 & Kabul \\
\hline $\mathbf{H}_{2}$ & $\mathrm{SMP} \rightarrow \mathrm{MCC}$ & 13,63 & 0,90 & $\mathbf{0 , 8 0}$ & Kabul \\
\hline $\mathbf{H}_{3}$ & $\mathrm{SMP} \rightarrow \mathrm{AK}$ & 14,02 & 0,88 & $\mathbf{0 , 7 0}$ & Kabul \\
\hline $\mathrm{H}_{4}$ & $\mathrm{SMP} \rightarrow \mathrm{MS}$ & 12,76 & 0,84 & 0,71 & Kabul \\
\hline
\end{tabular}

Yukarıdaki tabloya göre sosyal medya pazarlaması ile marka farkındalığı arasında pozitif yönlü ve anlamlı bir ilişki bulunmaktadır $(\mathrm{St}=0,95 ; \mathrm{t}$ değeri=13,04). Modelin açıklama gücü ise $\% 90$ olarak bulunmuştur. Buna göre araştırmanın birinci hipotezi "sosyal medya pazarlaması marka farkındalı̆̆ üzerinde etkilidir” kabul edilmiştir.

Sosyal medya pazarlaması ile marka çağrışımları arasında pozitif yönlü ve anlamlı bir ilişki bulunmaktadır $(\mathrm{St}=0,90$; $\mathrm{t}$ değeri=13,63). Modelin açıklama gücü ise $\% 80$ olarak bulunmuştur. Buna göre araştırmanın ikinci hipotezi "sosyal medya pazarlaması marka çağrışımları üzerinde etkilidir", kabul edilmiştir.
Sosyal medya pazarlaması ile algılanan kalite arasında pozitif yönlü ve anlamlı bir ilişki bulunmaktadır ( $\mathrm{St} .=0,88 ; \mathrm{t}$ değeri= 14,02). Modelin açıklama gücü ise $\% 70$ olarak bulunmuştur. Buna göre araştırmanın üçüncü hipotezi "sosyal medya pazarlaması algllanan kalite üzerinde etkilidir” kabul edilmiştir.

Sosyal medya pazarlaması ile marka sadakati arasında pozitif yönlü ve anlamlı bir ilişki bulunmaktadır ( $\mathrm{St} .=0,84 ; \mathrm{t}$ değeri= 12,76). Modelin açıklama gücü ise $\% 71$ olarak bulunmuştur. Buna göre araştırmanın üçüncü hipotezi "sosyal medya pazarlaması marka sadakati üzerinde etkilidir” kabul edilmiştir.

\section{Sonuç ve Tartışma}

Sürdürebilir bir rekabet avantaj1 elde etmek isteyen işletmeler açısından pazarlama stratejilerinde sosyal medya araçlarının kullanılması önemli bir gereklilik haline gelmiş bulunmaktadır. Sınırsız sayıda markalar arasında işletmelerin markalarının farkındalık ve çağrışımlarını artırabilmeleri, kaliteli hizmet sunumlarıyla marka müşteri ilişkisini uzun vadeye taşımaları doğrudan marka değerinin geliştirilmesine yönelik adımlardır. Söz konusu bu adımların atılması da sosyal medya araçlarının kullanılmasıyla daha kolay hale gelmiş bulunmaktadır. 
$\mathrm{Bu}$ çalışmada sosyal medya pazarlama faaliyetlerinin tüketici temelli marka değeri boyutları üzerindeki etkisi analiz edilmiştir. Araştırma sosyal medya araçlarını daha sık ve yoğun olarak kullanan üniversite öğrencileri üzerinde uygulanmıștır. $\mathrm{Bu}$ bağlamda Bingöl Üniversitesinde öğrenim görmekte olan 349 öğrenci ile yüz yüze görüşme yoluyla anket metodu uygulaması yapılmıştır. Araştırma verilerinin analizinde ise SPSS 18 ve LISREL 9.1 paket programlarından yararlanılmıştır.

Araştırma analizi sonucu elde edilen veriler doğrultusunda sosyal medya pazarlama faaliyetlerinin marka farkındalığı, marka çağrışımları, algılanan kalite ve marka sadakati boyutları üzerinde pozitif yönde ve etkili olduğu sonucuna ulaşılmıştır. Alan yazınında yapılan birçok çalışmada (Kavisekera ve Abeysekera, 2016; Balakrishnan vd. 2014; Erdoğmuş ve Çiçek, 2012; Godey vd. 2016; Luo vd. 2015; Gümüş vd., 2013; Çakırkaya ve Koçyiğit, 2019) bu sonuçları destekler niteliktedir.

$\mathrm{Bu}$ araştırmayla marka farkındalığı oluşturma, marka çağrışımlarını güçlendirme, algılanan kaliteyi artırma ve marka sadakat düzeyini daha da güçlendirmede sosyal medya pazarlama faaliyetlerinin etkisi olduğu görülmüştür. Analizler sonucu elde edilen bulgular doğrultusunda pazarlama ve marka yöneticilerinin tüketici nezdinde marka değerini artırabilmek amaciyla pazarlama stratejilerinde sosyal medya araçlarının kullanımına daha fazla önem vermeleri önerilmektedir. Araştırmanın sadece Bingöl Üniversitesinde öğrenim gören öğrencilerle sınırlı kalması ve sosyal medya pazarlamasının sadece tüketici temelli marka değeri boyutları üzerine etkilerinin analiz edilmesi bu araştırmanın önemli kısıtlarındandır. $\mathrm{Bu}$ vesileyle alan yazınında daha sonra yapılacak çalışmalarda farklı demografik niteliklere sahip tüketici gruplarına ulaşılmasıyla ve markanın farklı boyutlarının araştırmaya dâhil edilmesiyle daha farklı sonuçların elde edilebileceği de öngörülmektedir.

\section{Kaynakça}

Aaker, D.A.(1991). Managing brand equity: capitalizing on the equity of a brand name, new york: the free press maxwell macmillan international.

Ajanthan, D. (2017). The role of a social media marketing in building brand equity-a special reference to travel and tourism industry sri lanka. Global Journal of Management And Business Research.

Andéhn, M., Kazeminia, A., Lucarelli, A. \& Sevin, E. (2014). User-generated place brand equity on twitter: the dynamics of brand associations in social media, Place Branding and Public Diplomacy10(2132-144.

Balakrishnan, B. K., Dahnil, M. I. \& Wong, J. Y. (2014). The impact of social media marketing medium toward purchase intention brand loyalty, pp. 92-108.

Baydaş, A.,Ata S.,\& Berdibek, U. (2021). Sağlık kurumlarında sosyal medya pazarlaması, Sağlık Sektöründe uygulanan güncel pazarlama yaklaşımları,189.

Baydaş, A. \& Yaşar, M.E. (2019). Reklam ve etkili reklam unsurlarının belirlenmesine yönelik uygulamalı bir araștırma, USOBED Uluslararası Batı Karadeniz Sosyal ve Beşeri Bilimler Dergisi, 3(2): 204-217

Biyan, N. A. (2019). Tüketici temelli marka değerinin ölçümü: starbucks örneği. Alanya Akademik Bakış, 3(2), 151-164.

Blackston, M. (1992). Observations: building brand equity by managing the brand's relationships,Journal Advertising Research, Vol: 32 No: 3, 79-83.

Bong, W. Z. (2017). Influence of social media marketing, brand loyalty and ewom towards consumers' purchase intention (doctoral dissertation, Utar).

Christodoulides, G. \& De Chernatory, L. (2010). Consumerbased brand equity conceptualization and measurement. International Journal of Market Research 52(1) 43-66.

Çakırkaya, M.\& M. Koçyiğit, (2019). Sosyal medya iletişimi ve tüketici temelli marka değeri arasındaki ilişkinin incelenmesi: bir gsm markası üzerine tüketici araştırması. Işsletme Araştırmaları Dergisi 11(3), 2027 2039.

Elaydi, H. O. (2018). The effect of social media marketing on brand awareness through facebook: an -based perspective of mobile services sector in egypt, Open Access Library Journal 5(10), 1-5.

Erdogmus, I.E.,\& Cicek, M. (2012). The social media marketing brand loyalty, Procedia-Social Behavioral Sciences (58) 1353-1360.

Farquhar, P. H.(1989), Managing brand equity Marketing Research, September1(3), 24-34.

Gil, R. B., Adres, E. F. \& Salinas, E. M. (2007). Family as a source consumer-based brand equity. Journal Product Brand Management, 16 (3): 188-99

Godey B. , Aikaterini M., Daniele P., Joonas R., Gaetano A., \& Raffaele DRahul S.(2016). social media marketing efforts of luxury brands: influence on brand equity and consumer behavior Journal of Business Research 69(12): 5833-5841.

Gunelius S. (2010). 30-Minute social media marketing, Mcgraw Hill Publication.

Gümüş, N., Zengin, H. \& Geçti, F. (2013). Sosyal medya aracı olarak facebook uygulamalarının marka denkliği üzerindeki etkisi: bir gsm operatörünün facebook sayfası üzerinde araştırma. Sakarya İktisat Dergisi, 2(2), 87-117.

Hair, J., Anderson, R., Tatham, \& R.Black, W. (1998). Multivariate data analysis (5th ed.). Englewood Cliffs: Prentice Hall.

Hajli, N. M. (2014). A study of the 1mpact of social media on consumers International Journal of Market Research, 56(3): 387-404.

Kabani, S. \& Brogan, C. (2010). The zen of social media marketing. DallasTx: Benbella Books.

Kaplan, M. A. \& M. Haenlein (2010). Users of the world, unite! the challenges opportunities social media. Business Horizons, 53 (1), 59-68. 
Kavisekera, S. \& Abeysekera, N. (2016). Effect social media marketing on brand equity of Management \& Marketing Journal, 14(2).

Keller, K. L.(1993). Conceptualizing, measuring and managing customer-based brand equity Journal of Marketing Vol: 57, No: 1, 1-22.

Kimpakorn, N. \& Tocquer, G. (2010). Service brand equity employee brand commitment Journal of Services Marketing 24 (5). 378-388.

Kocatürk, E. B. (2017). Algılanan kaliteye ilişkin literatür taraması ve algılanan kalitenin artırılmasına yönelik öneriler. İstanbul Journal of Social Sciences Winter 15 43.

Kotler, P. \& Keller K.L. (2006). Marketing management, 12th edition, prentice hall, New Jersey.

Luo, Y., Jiang, H. \& Kulemeka, O. (2015). Strategic social media management and public relations leadership: insights from leaders, international Journal of Strategic Communication, 9(3), 167-196.

Low G.S. \& Lamb C. W. (2000). The measurement and dimensionalty of brand associations Journal of Product and Brand Management, Vol:9, No:6, 350-368.

Mousavi, J., Rad, H. S.\& Asayesh, N. (2015). The of social media on brand loyalty. Bulletin of the Georgian National Academy of Sciences, 9(2), 16-21.
Palumbo, F. \& P. Herbig (2000). The multicultural context of brand loyalty,European Journal of Innovation Management, 3(3), 116-124.

Schermelleh-Engel, K., H. Moosbrugger H. Müller (2003). Evaluating the fit of structural equation models: tests of significance and descriptive goodness-of-fit measures. Methods of Psychological Research Online.

Sin, S. S., Nor, K. M Al-Agaga, A. M. (2012). Factors affecting malaysian young consumers' online purchase intention social media websites. Procedia-Social And Behavioral Sciences, 40, 326-333.

Tang, XHawley, J.M. (2009). Measuring customer based brand equity: empirical evidence from the sportswear market china, Journal Of Product \& Brand Management, 18(4), 262-271

Thakur, M. K. \& Kumar, R.(2018). Importance and problems of social media marketing in Indian context, international Journal of Research in Management, Economics and Commerce, 08(02), Page 215-221

Yoo, B. \& N.Donthu (2001). Developing and validating a multidimensional consumer-based brand equity Scale, Journal of Business Research (52), 1-14. 


\section{Extended Abstract}

Social media tools are internet-based applications that allow users to create content and interact with ease. With the widespread use of social media tools in today's world, the world has become smaller and the interaction between people has increased even more. By using social media marketing, brands can reach consumers more easily and make their efforts to increase brand equity in a more meaningful way.

Social media platforms are one of the channels where consumers actively seek information about a product or service and can have an experience before purchasing. In this context, social media tools have also affected marketing activities such as advertising, marketing strategies and purchasing habits. Social media tools have an important place in maintaining activities that will provide competitive advantage for businesses such as creating awareness and associations about their brands, increasing perceived quality and expanding brand loyalty. It is an undeniable fact that businesses that have a privileged position in the minds of consumers and make them dependent on their own organizations are undoubtedly more successful and stable.

The use of social media tools in marketing also affects the brand equity of businesses and consumers' attitudes towards the brand. With a consumer-oriented approach, brand equity is expressed as an integrated form of the consumer's point of view towards the brand and the satisfaction obtained from that brand. Consumer-based brand equity is examined in many studies with the dimensions of brand awareness, brand associations, perceived quality and brand loyalty. Brand awareness is defined as the ability of a potential buyer to distinguish whether a brand is a member of a particular product category. The first step in creating brand equity starts with brand awareness.

The degree of recognition and remembrance of a brand is related to the level of awareness of that brand. Brand associations consist of all thoughts, feelings, perceptions, images, experiences, beliefs and attitudes about the brand. Brand associations are related to the communication aspect of the brand. It expresses how the characteristics of the brand are perceived by the consumers. Perceived quality is the customer's judgment about the overall excellence or superiority of a product that is different from objective quality and about the customer's perception. Brand loyalty is expressed as the customer's degree of loyalty to the brand. It is the customer's decisive approach to buying a brand, even in the face of more affordable pricing and promotional offers offered by competing businesses. Using social media tools can make it easier for brands to reach large audiences.

In this study, the effect of social media marketing activities on consumer-based brand equity dimensions (brand awareness, brand associations, perceived quality and brand loyalty) were analyzed. The sample of the study consisted of university students, since they were using social media more frequently in line with this purpose. It is anticipated that this study will provide a different perspective on the use and importance of social media tools in terms of both businesses and literature. In this study, the effect of social media marketing activities of businesses on consumer-based brand equity dimensions is analyzed. For this purpose, it was tried to analyze the perceptions and behaviors of university students towards brands, who frequently use social media tools. The research was conducted using a survey which was administered by face to face interviews with 349 students who were studying at Bingol University.

Considering many previous studies in the literature are analyzed, it is possible to say that there is a relationship between social media marketing and consumer-based brand equity dimensions. In line with these theoretical frameworks, four research hypotheses were constructed. Confirmatory factor analysis and structural equation modeling were used to analyze the data and test the research hypotheses.

As a result of the analysis, a positive and significant relationship was found between social media marketing and brand awareness. Accordingly, the first hypothesis of the study "social media marketing is effective on brand awareness" was accepted. There was a positive and significant relationship between social media marketing and brand associations. The second hypothesis of the study "social media marketing is effective on brand associations" was accepted. There was a positive and significant relationship between social media marketing and perceived quality.

Accordingly, the third hypothesis of the research which is "social media marketing is effective on perceived quality" was accepted. A positive and significant relationship was found between social media marketing and brand loyalty. Accordingly, the fourth hypothesis of the research "social media marketing is effective on brand loyalty" was accepted. The use of social media tools in marketing strategies has become an important requirement for businesses that want to gain a sustainable competitive advantage. Increasing awareness and association power among many brands and providing quality service are steps towards directly improving brand equity. Taking these steps became easier with the use of social media tools.

The present research, indicated that social media marketing activities had an effect on creating brand awareness, strengthening brand associations, increasing perceived quality and further strengthening the level of brand loyalty. In line with the findings obtained as a result of the analysis, it is recommended that marketing and brand managers pay more attention to the use of social media tools in their marketing strategies in order to increase the brand equity in the eyes of consumers.

For the limitations of this study, it can be said that it was restricted only to the students of Bingöl University and it only examined the effects of social media marketing on consumer-based brand equity dimensions. On this occasion, it is anticipated that different results can be obtained by reaching consumer groups with different demographic qualities in future studies in the literature and by including different dimensions of the brand in the research. 